\title{
COMUNICAÇÃO DE RESPONSABILIDADE SOCIAL EMPRESARIALL NO SETOR BANCÁRIO PORTUGUÊS
}

\section{COMMUNICATION OF CORPORATE SOCIAL RESPONSIBILITY IN THE PORTUGUESE BANKING SECTOR}

\author{
Sandrina Sobral ${ }^{1}$ \\ Clotilde Passos ${ }^{2}$
}

\begin{abstract}
Resumo: Num contexto moldado pela globalização, onde as organizações são obrigadas a ajustar os seus objetivos às mudanças ambientais e sociais mais notórias e à enunciada crise de valores, a sociedade despertou para a importância da responsabilidade social empresarial (RSE). A credibilidade e reputação são essenciais na promoção de um clima de confiança, no entanto, é necessário que a informação seja amplamente comunicada. Neste sentido, o objetivo deste estudo é efetuar um levantamento da tipologia das ações de RSE comunicadas pelo setor bancário português, bem como analisar a perceção dos bancários acerca da temática. $O$ estudo desenvolve-se segundo uma tipologia descritiva e exploratória e utiliza a metodologia de estudo de caso numa instituição bancária. Conclui-se que existe uma multiplicidade de ações divulgadas, nomeadamente ambientais, seguidas de sociais, maioritariamente destinadas à comunidade externa, amplamente conhecidas e reconhecidas pelos colaboradores. $O$ estudo fornece informações valiosas para os profissionais do setor e estabelece bases para futuras investigações.
\end{abstract}

Palavras-chave: Responsabilidade social empresarial. Comunicação organizacional. Sector bancário português.

\begin{abstract}
In a context shaped by globalization, where organizations are forced to adjust their objectives to the most notable environmental and social changes and the enunciated crisis of values, society has awakened to the importance of corporate social responsibility (CSR). Credibility and reputation are essential in promoting a climate of trust; information needs, however, to be widely communicated. In this sense, the purpose of this study is to carry out a survey of the typology of CSR actions communicated by the Portuguese banking sector as well as to analyze the bankers' perception about the subject. The study is
\end{abstract}

\footnotetext{
${ }^{1}$ Mestranda em Gestão na Universidade Católica Portuguesa - Viseu. E-mail: sandrinarsobral@gmail.com

${ }^{2}$ Doutorada em Gestão. Professora Auxiliar da Universidade Católica Portuguesa Viseu. E-mail: clotilde.passos@gmail.com
} 
developed according to a descriptive and exploratory typology and uses case study methodology in a banking institution. It is concluded that there is a multiplicity of publicized actions, namely environmental followed by social, mostly aimed at the external community, widely known and recognized by employees. The study provides valuable information for industry professionals and lays the foundation for future research.

Keywords: Corporate social responsibility. Organizational communication. Portuguese banking sector.

\section{INTRODUÇÃO}

O fenómeno da globalização, que obrigou ao ajustamento dos objetivos empresariais segundo uma visão sistémica em função das mudanças ambientais cada vez mais notórias, bem como a crise de valores sociais, despertou a comunidade para a importância da responsabilidade social. Hoje, é exigida uma postura de comprometimento empresarial (Neves, 2008), manifestada pela preocupação com as gerações futuras, resultando em benefícios reais e concretos para todos os envolvidos. Os gestores estão cada vez mais conscientes da importância e impacto das práticas socialmente responsáveis para a obtenção dos objetivos e do sucesso. A responsabilidade social empresarial (RSE) deve ser encarada como um investimento, conducente à definição de uma estratégia de longo prazo, promovendo a sustentabilidade a nível ambiental, económico e social e como forma de assegurar vantagens competitivas.

A comunicação surge como fator-chave do sucesso operacional ao envolver toda a comunidade empresarial por via da formulação de um planeamento bem estruturado, a nível interno e externo (Rumo, 2006). Na literatura, é por diversas vezes associado o processo de comunicação de RSE à imagem e reputação empresarial (Faria, 2015) sendo, no entanto, mais escassos os estudos à volta das práticas adotadas e ainda mais quando associamos ao setor bancário (Douglas, Doris, \& Johnson, 2004).

Diante dessas considerações, a questão principal que norteia este estudo é: quais as ações de RSE divulgadas pelo setor bancário português?

O objetivo geral é efetuar um levantamento das ações de RSE divulgadas por uma instituição bancária portuguesa, classificando-as quanto à sua tipologia. Este objetivo dá origem a três objetivos específicos:

a) Comparar estas ações e respetiva tipologia com as adotadas por outra instituição bancária; 
b) Analisar a perceção dos colaboradores acerca da temática e da sua divulgação;

c) Propor a implementação de iniciativas de RSE.

Para a concretização dos objetivos foi adotada uma abordagem qualitativa do tipo descritivo e exploratório e recorreu-se à metodologia de estudo de caso, com recurso a entrevistas escritas e análise documental. Desta forma, o estudo vem contribuir para reduzir a escassez de informação existente sobre esta temática.

O estudo inicia-se com a introdução, seguida da fundamentação teórica dos dois conceitos em estudo, a comunicação organizacional e a responsabilidade social empresarial e uma subsecção, onde se relacionam ambos os termos. Na segunda parte surge a caraterização da investigação. Por último, na terceira parte são apresentados e discutidos os resultados, tendo em consideração as ações divulgadas pelas instituições bancárias alvo de análise, bem como o feedback dos colaboradores acerca desta temática. Foi ainda apresentado um conjunto de sugestões de iniciativas de RSE, passíveis de implementar pelas instituições bancárias.

\section{REFERENCIAL TEÓRICO}

\subsection{Comunicação organizacional}

A comunicação é intrínseca à vivência em sociedade e começa por ser encarada como um processo simplificado, no qual participa um emissor e um recetor, com uma mensagem a transmitir (Bilhim, 1996). A comunicação deve ser do emissor para o recetor, mas é igualmente relevante que este último transmita o seu feedback da informação ao seu emissor (Teixeira, 2005).

Bilhim (1996) apresenta três tipos de comunicação: intrapessoal, interpessoal e organizacional. Para este estudo, é conveniente debruçarmonos sobre a comunicação organizacional. Surge na literatura como um processo complexo, específico e simultaneamente global, dado o elevado número de intervenientes. É um conceito vastamente definido ainda assim considerado redutor dada a sua extensão (Ruão, 1999).

Tradicionalmente, o funcionamento das organizações dependia da interação comunicacional entre os membros de hierarquias superiores podendo ser feita por via formal ou informal (Cardoso, 2006). A comunicação formal diz respeito a princípios orientadores já estabelecidos surgindo como os mais adotados nas organizações e os mais preferidos pelos superiores hierárquicos. Ao contrário, os canais informais funcionam 
quase como um "passa a palavra" (Bilhim, 1996). Teixeira (2005) refere a comunicação "em gravinha" que, para além de envolver simultaneamente várias hierarquias surge de várias direções. É considerada como primária pelos colaboradores uma vez que possibilita a circulação da informação de uma forma mais rápida.

Segundo Bilhim (1996), a comunicação surge de certo modo limitada e restrita ao superior hierárquico, contudo, se assim não fosse, a sua eficácia estaria comprometida, dada a elevada quantidade de mensagens que poderia originar. Já Cardoso (2006) refere que o fenómeno de globalização, a revolução tecnológica e de informação e a crescente exigência do meio envolvente levam as organizações a apostar cada vez mais na comunicação de uma forma estratégica. Assim, além de envolverem todas as hierarquias internas apostam nas suas relações institucionais e desta forma, faculta a criação de valor para a estratégia global da organização e possibilita o seu crescimento com base nos princípios sociais e éticos.

Monteiro (2012) destaca o planeamento como o principal fator de sucesso na transmissão de informação, ao referir “(...) apesar do reconhecimento da importância da comunicação, esta não ser muitas vezes bem planeada e serem cometidos erros que podem por em risco a relação da organização com os seus colaboradores e, a seu tempo, relevar efeitos muito prejudiciais para a organização." (p. 90).

Kunsch (2011) defende "a adoção, por parte das organizações, de uma filosofia de comunicação integrada e a não-fragmentação dessa comunicação" (p. 73), importante no relacionamento com as partes interessadas, designadas de stackeholders (Brambilla, Candido, \& Gusatti, 2016; Lungu, Caraiani, Dascalu, \& Guse, 2011; Surroca, Tribó, \& Waddock, 2010), a nível interno (fazendo dos seus colaboradores aliados) e a nível externo (criando uma relação de confiança com a comunidade). Deste modo, o comportamento corporativo deve ser encarado na sua totalidade, no sentido da formação de uma imagem e reputação una (Magalhães, 2010; Parisotto \& Souza, 2012; Zientara, 2017).

Importa ainda, de entre as várias formas de divulgação, apontar as mais eficazes na transparência da imagem e reputação corporativa. A tipologia escrita surge como a mais utilizada, traduzida na informação contida nas páginas web das organizações. Trata-se do canal de comunicação mais utilizado pelas empresas, dada a fácil acessibilidade, usabilidade e abrangência desta plataforma (Faria, 2017; Rego, 1999). 


\subsection{Responsabilidade social empresarial (RSE)}

Uma organização pode ser definida tendo em conta duas perspetivas, por um lado, como unidade geradora de valor económico acrescentado, por outro lado, como um conjunto de condutas sociais coordenadas com vista a alcançar determinados objetivos traçados (Bilhim, 1996).

Para além da organização ter uma responsabilidade económica que busca a obtenção de lucros por via da venda de produtos, o pagamento de salários aos seus colaboradores e a responsabilidade legal, imposta por normativos específicos, tem um compromisso assumido com a sociedade.

$\mathrm{O}$ conceito de responsabilidade social surgiu na década de sessenta do século XX, nos Estados Unidos da América. Apresenta uma evolução conceptual, com inclusão de novas dimensões, devido à crescente exigência, atenção e valorização pela sociedade (Duarte, Rodrigues \& Sotomayor, 2014).

O Livro Verde descreve a RSE como "a integração voluntária de preocupações sociais e ambientais por parte das empresas nas suas operações e na sua interação com outras partes interessadas" (Europeia, 2001, p.7).

São várias as teorias e abordagens sobre a RSE (Duarte et al., 2014; Faria, 2017) não obstante, para o presente estudo, são apresentadas a visão clássica de Friedman e duas teorias mais contemporâneas, como a teoria dos stakeholders e a teoria da legitimidade.

A visão clássica, considerada a mais elementar, tem como conhecido defensor o nobel americano Milton Friedman (Teixeira, 2005). Assenta na mera obtenção de resultados económicos, por forma a remunerar os acionistas, existindo uma mera preocupação social quanto à definição das estratégias empresariais económicas e financeiras (Duarte et al., 2014; Friedman, 1970). Assim, a sociedade é favorecida pela mera "participação lucrativa" das organizações (Teixeira, 2005).

$\mathrm{Na}$ teoria dos stakeholders, são tidas em consideração todas as partes interessadas que afetam a atividade da empresa, privilegiando uma visão global e não apenas os interesses individuais, como a teoria clássica defendia (Greenwood \& Cieri, 2005; Freeman, 2004).

A teoria da legitimidade surge como explicação à necessidade de divulgação pelas empresas de ações de RSE afetando o entendimento do exterior (Deegan, 2002). Fornece elementos para a melhor compreensão das motivações dos gestores na utilização de instrumentos de divulgação para benefício da organização, embora com fundamentos a necessitarem de aperfeiçoamento (Eugénio, 2010). 
De acordo com o Livro Verde, a RSE assenta em três áreas: social, ambiental e económica, fundamentando os 3P's (Planet, Profit, People) da sustentabilidade (Europeia, 2001). A estratégia de RSE envolve duas dimensões: a interna e a externa. Na dimensão interna, as empresas preocupam-se com questões ligadas ao relacionamento laboral, como a gestão de recursos humanos (práticas não discriminatórias de remuneração e género, segurança laboral e formação ao longo da vida), adaptação à mudança e gestão do impacto ambiental e recursos naturais. Na dimensão externa, enquadram-se questões relacionadas com as comunidades locais, parceiros comerciais: clientes e fornecedores, concorrência e acionistas/sócios. Neste âmbito, os consumidores/clientes são tidos como o primeiro alvo das ações de RSE, onde se enquadram a qualidade e segurança dos produtos, a justiça na definição do preço e a transparência publicitária. O meio ambiente apresenta-se especialmente impactante na opinião pública nos últimos tempos. Os efeitos são notórios e as organizações apostam na redução do consumo dos recursos naturais (água, energia, emissões atmosféricas e papel), bem como nas medidas de prevenção como a criação de processos de tratamento de resíduos e utilização de fontes alternativas renováveis (Faria, 2017; Marco, 2012; Teixeira, 2005).

Já Faria (2017), ao estudar as ações de RSE mais divulgadas por diversos setores de atividade, conclui que o grupo mais abrangido pelas práticas empreendidas são os colaboradores. Destacam-se ainda como principais ações diligenciadas, a contratação de pessoas com deficiência bem como a atribuição de uma remuneração acima da média.

Salienta-se que a estratégia de RSE não deve dissociar qualquer item, por forma a não gerar um eventual sentimento discriminatório das partes envolvidas (Marco, 2012), tendo em consideração processos e práticas favoráveis ao seu alinhamento estratégico (Barakat \& Polo, 2016; McWilliams \& Siegel, 2011; McWilliams, Siegel, \& Wright, 2006). São exemplos o diálogo com stakeholders, vínculo das práticas com a atividade principal da empresa, envolvimento das hierarquias superiores, envolvimento das áreas funcionais, monitorização e gestão de resultados e melhoria do contexto competitivo (Simone Ruchidi Barakat, Boaventura, \& Polo, 2017).

\subsection{Comunicação de responsabilidade social no setor bancário}

A comunicação surge como fator essencial na promoção da estratégia da RSE, pois torna possível a transmissão de novos produtos, serviços e transformações organizacionais (Marco, 2012). Particularmente, a 
comunicação interna funciona como um instrumento que proporciona ao trabalhador integrar-se e comprometer-se com o negócio enquanto parceiros, permitindo dinamizar práticas de responsabilidade social, que são fundamentais para o processo de divulgação das metas e da sua concretização permitindo uma intervenção mais rápida e eficaz (Duarte et al., 2014).

A nível europeu, a política de RSE apresentada pela Comissão Europeia (2001) destaca como ação a desenvolver, a aposta na visibilidade e divulgação de práticas responsáveis e concretiza-as por via da criação de um prémio europeu, bem como uma plataforma onde pretende expor ações e monitorizá-las conjuntamente com as empresas.

Teixeira (2005) destaca a premência da qualidade da informação prestada pois "os investidores sublinham a necessidade de melhorar a divulgação de informação e a transparência quanto às práticas das empresas, e as organizações de consumidores salientam a importância de dispor de informações fiáveis sobre as condições de produção e venda de bens." (p. 284).

$\mathrm{Na}$ atualidade portuguesa, a comunicação de temas relacionados com a RSE não tem carácter normativo por parte das empresas (Rumo, 2006). Excecionalmente, no setor financeiro, nomeadamente a banca e seguros, foi determinada, desde 2015, a conveniência na apresentação do relato integrado baseado na inclusão no relatório anual de contas de informações relevantes no âmbito da sustentabilidade (Faria, 2017). O Decreto-lei n. ${ }^{\circ}$ 89/17 de 28 de julho do Ministério das Finanças (2017) veio obrigar à divulgação de informação não financeira por entidades de interesse público e que tenham em média mais de 500 colaboradores durante o exercício anual, introduzindo na legislação portuguesa a diretiva europeia 2014/95/EU. As informações não financeiras dizem respeito às áreas ambientais, sociais, aos trabalhadores, à igualdade entre mulheres e homens, à não discriminação, ao respeito dos direitos humanos, ao combate à corrupção e às tentativas de suborno (Decreto Lei no 89/17 de 28 de julho do Ministério das Finanças, 2017).

De forma ligeira, pode-se crer que o setor bancário não produz grandes efeitos na comunidade, nomeadamente ambientais, uma vez que não se trata de um setor de produção intensiva com utilização de recursos nocivos e danosos. Contudo, este setor pode ser encarado como potenciador deste tipo de atividades, ao facilitarem a sua continuidade por via de financiamentos concedidos (Thompson \& Cowton, 2004). Adicionalmente, matérias como o consumo de papel, energia, água colocam este setor igualmente nesta discussão (Branco \& Rodrigues, 
2006). No estudo de Amorim (2010), a par do setor das telecomunicações surge o setor financeiro (onde se inclui a banca), como os que mais divulgam ações de RSE. Deste modo, o sistema bancário, no âmbito das suas funções, recorre cada vez mais à verificação de aspetos sociais e ambientais como instrumento de avaliação no que concerne aos eventuais riscos operacionais na concessão de financiamento, constituindo um indicador credível da qualidade de gestão (Europeia, 2001).

Faria (2017) estudou a informação constante em 77 páginas web, onde estavam contempladas empresas ligadas ao setor da banca, encontrando terminologia como "educação, saúde, cultura, assistência social, sustentabilidade e ambiental" (p.548).

Andrikopoulos, Samitas, e Bekiaris (2014) analisaram noventa e três sites institucionais de sociedades financeiras, onde destacam a dimensão da amostra como a mais expressiva na literatura até à data. Neste estudo verificaram que “(...) a divulgação ética é mais extensa do que a divulgação de práticas ambientais ou de RSE (...)" justificando o resultado com base em "critérios que são importantes para as instituições financeiras e estão incluídos na divulgação da ética, como "relações com investidores", "política de investimento" e "ética comercial" (p. 31).

Rodrigues (2013) analisou as tendências de difusão de RSE em 10 bancos portugueses, no período de 2002 a 2011, verificando um aumento da divulgação, por parte das entidades bancárias, no período pós-crise, com base nos relatórios anuais e de sustentabilidade. É notório o impacto da crise financeira internacional, levando a um ajustamento da filosofia da banca, ao incluir programas para a educação financeira com o objetivo de divulgar informações sobre produtos financeiros e sua correta utilização (Matei \& Voica, 2013).

Num estudo comparativo, com uma amostra de seis bancos irlandeses e quatro europeus verificou-se que, o último grupo apresentou informação divulgada nos relatórios anuais de gestão em maior quantidade e qualidade. Surgem como principais preocupações da banca europeia: "community involvement, human resources and corporate governance" (Douglas, Doris, \& Johnson, 2004, p.392).

Quando se pretende analisar informação de responsabilidade social num determinado setor ou empresa, verifica-se que o meio preferencial adotado é a visualização da página web institucional. Deste modo, pretendem abranger ao máximo o seu público-alvo (Andrikopoulos et al., 2014; Gill, Dickinson \& Scharl, 2008; Douglas, Doris, \& Johnson, 2004; Faria, 2017; Silva, 2014). 
Como o intuito de avaliarem a preferência de divulgação de informação, por empresas da Euronext Lisboa, entre os relatórios tradicionais e as páginas da Internet Branco \& Rodrigues (2008) concluíram que depende do público-alvo. Ou seja, os relatórios de gestão despertam mais a atenção dos investidores enquanto as páginas web despertam mais o público em geral. No setor bancário, Douglas et al.,(2004) aferiram que, em seis bancos irlandeses, a informação de RSE fazia-se sentir mais nas suas páginas web do que nos relatórios de gestão.

\section{METODOLOGIA}

A metodologia utilizada classifica-se como qualitativa, com uma análise exploratória sobre a informação contida na página web institucional. Como referido por Gil (2008), a análise exploratória é uma mais-valia para estudo de temáticas pouco estudadas, contribuindo para melhor identificação e familiarização do problema. A investigação da página web é utilizada e referida por muitos autores como essencial na divulgação de RSE (Andrikopoulos et al., 2014; Branco \& Rodrigues, 2008; Thompson \& Cowton, 2004; Douglas et al., 2004; Faria, 2015, 2017). Paralelamente foi realizada uma análise de conteúdo permitindo uma descrição direcionada e metódica com vista à interpretação das informações contidas (Gil, 2008). É considerada a principal técnica utilizada para estudar a divulgação de responsabilidade social nos websites das empresas (Patten, 2002).

A utilização de um estudo de caso permitiu um conhecimento mais amplo e detalhado, facilitando a investigação do fenómeno da RSE num contexto real, sendo utilizado por diversos autores (Gil, 2008). Como instrumento de recolha de dados e como complemento ao estudo de caso, foram utilizadas sete entrevistas escritas e análise documental. Esta última permite uma análise comparativa entre as informações de RSE divulgadas entre duas instituições bancárias, aferindo semelhanças e disparidades.

A escolha recaiu sobre duas entidades bancárias com forte posição e relevância económica nacional, a Caixa Geral de Depósitos, S.A., CGD, enquanto estudo de caso, e o Banco Comercial Português, ou Millennium BCP, enquanto entidade de discussão. São das maiores instituições bancárias a operar em Portugal, havendo evidência empírica que relaciona positivamente o tamanho do banco com o nível de informação de RSE divulgada (Almeida, Silva, \& Oliveira, 2015; Braga, Oliveira, \& Salotti, 2009). 
As entrevistas são uma forma de "interação social" facultando informações tendo em conta a perceção das pessoas em contexto real, neste caso laboral (Gil, 2008, p.109). Optou-se por entrevistas escritas, de forma estruturada, por facilitar a recolha em diferentes agências bancárias portuguesas.

\section{ANÁLISE E DISCUSSÃO DOS RESULTADOS}

Procedeu-se à análise da informação contida na página oficial da CGD (www.cgd.pt), em dezembro de 2017, não tendo sido consideradas eventuais ligações externas à página principal. Por forma a organizar a informação recolhida foram listadas as ações (iniciativas) divulgadas, agrupando-as de acordo com as partes envolvidas visadas, comunidade e ambiente. Foram ainda classificadas de acordo com o seu impacto a nível ambiental, social e económico.

Verifica-se que as ações divulgadas têm como principal alvo a comunidade em geral. Isto vai ao encontro do estudo de Faria (2015), justificando a possibilidade de inclusão de várias temáticas e do alcance que as páginas da web proporcionam.

Neste campo de ação, são divulgadas iniciativas associadas à comercialização de produtos bancários que, para além do natural interesse económico, assumem outras dimensões, maioritariamente sociais, tentado colmatar eventuais falhas na oferta bancária em geral. Constatam-se ainda preocupações com a formação e promoção do conhecimento na sociedade, apostando em diversas atividades culturais, musicais e de literacia financeira fundamental na gestão de futuro. O comprometimento dos jovens é outra valência, com aposta em atividades de voluntariado. $\mathrm{Na}$ dimensão ambiental, a redução de consumo de energia, emissões atmosféricas e consumíveis e a reflorestação e a manutenção da floresta assumem-se como principais preocupações da CGD.

O foco social ou ambiental está sempre presente em todas as ações da CGD, já o económico surge com menos expressão. Isto pode estar relacionado com o receio da instituição no conflito de interesses económicos, por parte do público, na promoção destas iniciativas, conforme Faria (2017) referiu no seu estudo.

Com o intuito de avaliar eventuais semelhanças ou diferenças na divulgação de ações de RSE no setor bancário, procedeu-se à análise da informação constante na página web de outra entidade bancária, o Millennium BCP, visto ser o maior banco privado em Portugal (BCP, 
2017). O procedimento de recolha, organização e análise foi similar ao aplicado no caso de estudo.

Numa primeira impressão, verifica-se grande quantidade de ações de RSE divulgadas pela instituição, ao expor não só iniciativas recentes, como um rol de ações realizadas desde 2010, que pode ser explicado pelo interesse histórico, pelo carácter de continuidade que pretende demonstrar, ou como mero aglomerado de informação passada.

São divulgadas mais iniciativas sociais do que ambientais. No âmbito de ações sociais, é incluída a comunidade interna - os seus colaboradores, com iniciativas de concessão de crédito bonificado, acesso a subsistema de saúde, formação superior financiada, acesso a serviços médicos próprios e atendimento bancário personalizado. No âmbito da comunidade externa surge o voluntariado, com a dinamização de projetos próprios e de parceria com outras entidades consideradas de referência, a promoção da cultura, o programa de literacia financeira nas escolas e a recolha de consumíveis pelos vários balcões, com vista ao apoio de diversas IPSS.

No campo de ação da gestão ambiental destacam-se mais matérias de redução dos consumos energéticos internos, descritos de uma forma mais informativa, com linhas orientadoras e de avaliação da performance, do que propriamente de execução como verificado na CGD. A promoção da reflorestação do país é uma preocupação de ambas as instituições, revelando um empenho e um resultado idêntico.

Por último, e à semelhança da CGD, são comunicados produtos financeiros comercializados que têm associado o conceito de responsabilidade social, como linhas de microcrédito direcionada a clientes sem acesso ao crédito comum, a oferta exclusiva e segmentada e o apoio a clientes com necessidades financeiras.

Com o intuito de analisar a perceção dos colaboradores acerca da temática e sua divulgação, foram selecionados de forma probabilística, por conveniência, sete colaboradores de uma instituição bancária portuguesa. Foram realizadas sete entrevistas escritas e enviadas para os entrevistados, via correio eletrónico, por forma a obter as suas respostas. O guião contemplava uma breve explicação quanto à finalidade desta investigação, bem como a garantia de confidencialidade no tratamento dos dados.

A análise das entrevistas escritas é apresentada em três fases. Começa por ser definido o perfil sociodemográfico dos colaboradores (Quadro I), em seguida são apresentadas e comentadas as principais reflexões baseadas nas respostas e, por último, são expostas sugestões 
fornecidas pelos próprios colaboradores de iniciativas passíveis de implementação no âmbito da RSE.

Quadro I

Perfil sociodemográfico dos entrevistados

\begin{tabular}{|c|c|c|c|c|c|}
\hline Idade & Género & $\begin{array}{c}\text { Habilitações } \\
\text { Literárias }\end{array}$ & $\begin{array}{c}\text { Cargo } \\
\text { desempenhado }\end{array}$ & $\begin{array}{c}\text { Antiguidade } \\
\text { na } \\
\text { organização }\end{array}$ & $\begin{array}{c}\text { Antiguidade } \\
\text { na função }\end{array}$ \\
\hline $\begin{array}{l}\text { Idade mínima - } \\
26 \text { anos; idade } \\
\text { máxima - } 54 \\
\text { anos; idade } \\
\text { média - } 42,3 \\
\text { anos }\end{array}$ & $\begin{array}{l}\text { Masculino } \\
(57 \%) ; \\
\text { feminino } \\
(43 \%)\end{array}$ & $\begin{array}{l}\text { Licenciatura } \\
(100 \%)\end{array}$ & $\begin{array}{l}\text { Subordinados } \\
(71,4 \%) \mathrm{e} \\
\text { Gerência } \\
(28,6 \%)\end{array}$ & $\begin{array}{l}\text { Mínimo - } 1 \\
\text { ano; máximo } \\
-27 \text { anos; } \\
\text { média - } 18,14 \\
\text { anos }\end{array}$ & $\begin{array}{l}\text { Mínimo - } 1 \\
\text { ano; máximo } \\
-27 \\
\text { anos; média - } \\
9,43 \text { anos }\end{array}$ \\
\hline
\end{tabular}

Conclui-se que a maioria dos respondentes (57\%) é do sexo masculino. A idade média dos respondentes é de 42,3 anos, com uma amplitude máxima e mínima de 28 anos. Do total dos entrevistados, todos possuem o ensino superior licenciatura, $28,8 \%$ exercem cargos de gerência e os restantes exercem outras funções subordinadas. Em média, trabalham há 18 anos na instituição e há 9 anos no mesmo serviço.

Através da leitura do Quadro II, constata-se que, globalmente, os colaboradores mostram amplo conhecimento do conceito de RSE, ao utilizarem maioritariamente terminologia como preocupação, adoção de comportamentos, respeito, promoção e disposição de meios. Os stakeholders mais referidos foram o meio ambiente e a comunidade. Foram apontadas mais iniciativas de carácter ambiental do que social, não tendo sido referidas quaisquer ações direcionadas aos próprios colaboradores. Por um lado, pode significar menor divulgação pela instituição e, por outro lado, a não identificação dessas medidas como práticas de RSE. A identificação das motivações da instituição mostrouse diversificada, baseadas na preocupação social, económica e até na motivação dos colaboradores. Diversos autores apontam como principal fator o desejo de legitimidade da atividade de uma instituição (Cormier \& Gordon, 2001; Deegan, 2002; Eugénio, 2010; O’Donovan, 2002; Wilmshurst \& Frost, 2000). Segundo os autores, Penha, Andrade, Cabral e Parente (2013), a adoção da RSE pela banca não é determinada pela concorrência nem pela maior exigência por parte dos clientes, mas sim por uma questão reputacional. 
Quadro II

Tópicos de resposta dos entrevistados

\begin{tabular}{|c|c|}
\hline Questões & Tópicos de resposta \\
\hline $\begin{array}{l}\text { O que entende } \\
\text { por RSE? } \\
\text { Entende que este } \\
\text { conceito se } \\
\text { coaduna com os } \\
\text { valores da } \\
\text { instituição? }\end{array}$ & $\begin{array}{l}\text { - Preocupação com os clientes, colaboradores e meio ambiente; } \\
\text { - Respeito pelos outros, honestidade, empreendedorismo, } \\
\text { clareza; } \\
\text { - Adoção de comportamentos e ações para promover o bem- } \\
\text { estar interno e externo; } \\
\text { - Disposição de meios e soluções às populações e empresas } \\
\text { para além da remuneração do acionista. } \\
\text { Todos os participantes referiram que o conceito se coaduna } \\
\text { com os valores da instituição. }\end{array}$ \\
\hline $\begin{array}{l}\text { Quais os projetos } \\
\text { de RSE } \\
\text { dinamizados pela } \\
\text { instituição que } \\
\text { conhece? }\end{array}$ & $\begin{array}{l}\text { - Abertura de contas solidárias; } \\
\text { - Reciclagem de cartões bancários; } \\
\text { - Redução no consumo de energia elétrica com instalação de } \\
\text { painéis fotovoltaicos e a reutilização das águas das chuvas; } \\
\text { - Promoção de recolhas de sangue; } \\
\text { - Criação de protocolos para apoio social; } \\
\text { - Incorporação dos princípios de global compact e os objetivos } \\
\text { do desenvolvimento sustentável; } \\
\text { - Redução do consumo de papel, com emissão comunicações } \\
\text { eletrónicas; } \\
\text { - Não oferta de brindes a clientes, normalmente desperdiçados; } \\
\text { - Custos de manutenção de conta mediante o património } \\
\text { financeiro do cliente; } \\
\text { - Projetos de voluntariado. }\end{array}$ \\
\hline $\begin{array}{l}\text { Quais pensam ser } \\
\text { as motivações da } \\
\text { instituição } \\
\text { quando pratica } \\
\text { RSE? }\end{array}$ & $\begin{array}{l}\text { - Preocupação social, económica (redução de custos internos) e } \\
\text { ambiental e de sustentabilidade; } \\
\text { - Demonstrar outras preocupações além da busca do lucro; } \\
\text { - Defesa da instituição e reputação interna e externa; } \\
\text { - Fidelização de clientes; } \\
\text { - Maior exigência da comunidade e da concorrência; } \\
\text { - Motivação dos colaboradores. }\end{array}$ \\
\hline
\end{tabular}

Como complemento ao estudo e com base nas entrevistas realizadas, foram apontadas pelos entrevistados, iniciativas que gostariam de ver implementadas, dada a sua relevância para a instituição e comunidade. Estas iniciativas apresentam-se e explicam-se, tendo em conta a sua implementação e resultados, no Quadro III. 
Quadro III

Sugestões de iniciativas propostas pelos entrevistados

\begin{tabular}{|c|c|}
\hline Iniciativas & Implementação e resultados \\
\hline Publicidade digital & $\begin{array}{l}\text { Colocação de painéis virtuais de publicidade em substituição dos } \\
\text { cartazes em papel. }\end{array}$ \\
\hline $\begin{array}{l}\text { Monitores } \\
\text { interativos }\end{array}$ & $\begin{array}{l}\text { Colocar o preçário ao dispor dos clientes através de monitor, } \\
\text { permitindo a redução do consumo de papel através da sua } \\
\text { disponibilização e atualização automáticas. }\end{array}$ \\
\hline $\begin{array}{c}\text { Dia do } \\
\text { voluntariado }\end{array}$ & $\begin{array}{l}\text { Promover a participação em iniciativas com o encerramento das } \\
\text { agências um dia por ano, envolvendo todos os colaboradores. }\end{array}$ \\
\hline $\begin{array}{l}\text { Proximidade com } \\
\text { IPSS }\end{array}$ & $\begin{array}{l}\text { Promover ações com as IPSS locais por forma a garantir mais } \\
\text { proximidade da instituição com as realidades apoiadas. }\end{array}$ \\
\hline $\begin{array}{l}\text { "Pulmão } \\
\text { saudável" }\end{array}$ & $\begin{array}{l}\text { Incentivo aos colaboradores a abandonar vícios tabágicos } \\
\text { através da comparticipação dos tratamentos necessários bem } \\
\text { como atribuição de um prémio monetário em caso de sucesso. }\end{array}$ \\
\hline $\begin{array}{l}\text { Mobilidade } \\
\text { interna }\end{array}$ & $\begin{array}{l}\text { Aproximação do local de trabalho à residência dos } \\
\text { colaboradores, conjugando de uma forma mais facilitada a vida } \\
\text { familiar e profissional. }\end{array}$ \\
\hline $\begin{array}{l}\text { Descentralização } \\
\text { dos serviços }\end{array}$ & $\begin{array}{l}\text { Promoção do desenvolvimento do interior por via da } \\
\text { transferência de serviços da instituição para estas zonas. }\end{array}$ \\
\hline
\end{tabular}

Tendo em vista o aprofundamento e contributo na dinamização de ações sociais e ambientais em prol da comunidade, interna e externa, assumindo o papel potenciador de melhoria social, são apresentadas ações de responsabilidade social passíveis de implementação. Algumas destas iniciativas foram redesenhadas a partir do exemplo de outras, publicadas no "Guia responsabilidade social das PME", elaborado por Grace (2014), outras são sugestão própria (Quadro IV). 
Quadro IV

Sugestões de iniciativas no âmbito de RSE

\begin{tabular}{|c|c|c|}
\hline & Iniciativas & Implementação e resultados \\
\hline \multirow{4}{*}{ 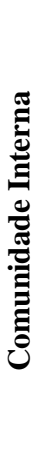 } & $\begin{array}{l}\text { Oferta do dia de } \\
\text { anos do (s) filho (s) }\end{array}$ & $\begin{array}{l}\text { Importante no relacionamento e conciliação da vida } \\
\text { familiar e profissional. }\end{array}$ \\
\hline & $\begin{array}{l}\text { Formação em } \\
\text { segurança laboral }\end{array}$ & $\begin{array}{l}\text { Ações semestrais promovendo maior sensibilização e } \\
\text { preparação dos colaboradores em matérias como a } \\
\text { segurança (p. ex. situação de assalto). }\end{array}$ \\
\hline & $\begin{array}{l}\text { Apoio às } \\
\text { atividades lúdicas }\end{array}$ & $\begin{array}{l}\text { Parcerias com negócios locais no sentido de } \\
\text { proporcionar aos seus colaboradores momentos de } \\
\text { relaxamento e diversão (atividades de desporto, cultura } \\
\text { e música). }\end{array}$ \\
\hline & $\begin{array}{l}\text { Continuidade em } \\
\text { situação de } \\
\text { reforma }\end{array}$ & $\begin{array}{l}\text { Envio de comunicações anuais mencionando aspetos } \\
\text { importantes alcançados mantendo uma relação estreita } \\
\text { do ex. colaborador com a instituição. }\end{array}$ \\
\hline \multirow{5}{*}{ 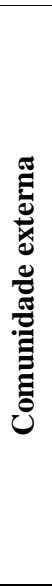 } & $\begin{array}{l}\text { Projeto dadores de } \\
\text { sangue }\end{array}$ & $\begin{array}{l}\text { A ocorrer nos meses de férias de verão quando o Instituto } \\
\text { Português de Sangue recolhe menos doações. }\end{array}$ \\
\hline & $\begin{array}{l}\text { Barómetro de } \\
\text { satisfação do } \\
\text { cliente }\end{array}$ & $\begin{array}{l}\text { Serviço a ser disponibilizado no acesso online do Banco } \\
\text { onde, após uma visita à agência no âmbito de alguma } \\
\text { operação financeira, o cliente poderá avaliar a qualidade } \\
\text { do atendimento. O feedback proporcionará a } \\
\text { implementação de ações de melhoria. }\end{array}$ \\
\hline & $\begin{array}{l}\text { Reflorestamento } \\
\text { local }\end{array}$ & $\begin{array}{l}\text { Em parceira com as autarquias os colaboradores são } \\
\text { levados à participação na reflorestação de uma área } \\
\text { local. }\end{array}$ \\
\hline & $\begin{array}{l}\text { Ações temáticas } \\
\text { solidárias }\end{array}$ & $\begin{array}{l}\text { Integrar nas ações lúdicas da empresa projetos de } \\
\text { voluntariado: ações sociais como jantar de Natal ou uma } \\
\text { caminhada podem gerar receitas para IPSS locais. }\end{array}$ \\
\hline & $\begin{array}{l}\text { Adaptação das } \\
\text { instalações à } \\
\text { entrada }\end{array}$ & $\begin{array}{l}\text { Implementação de portas de abertura automática ou por } \\
\text { acionamento, permitindo que pessoas com mobilidade } \\
\text { reduzida consigam aceder com facilidade às instalações. }\end{array}$ \\
\hline
\end{tabular}

\section{CONCLUSÃO}

A responsabilidade social das empresas tem alcançado cada vez mais seguidores, fruto da maior visibilidade e dimensão dos impactos ambientais, bem como da visão sistémica da sociedade, exigindo ao tecido empresarial mais do que a mera garantia da gestão do negócio e dos postos de trabalho mas uma preocupação global. A comunicação surge como um fator essencial na difusão das iniciativas realizadas, podendo contribuir para a propagação de boas práticas, motivando outras organizações à sua adoção e cooperação, tendo em conta os princípios sociais e éticos.

Os resultados revelaram multiplicidade de ações divulgadas, nomeadamente ambientais, seguidas de sociais, maioritariamente destinadas à comunidade externa, amplamente conhecidas e reconhecidas 
pelos colaboradores. É possível inferir que independentemente da natureza da organização, pública ou privada, a preocupação com a comunicação de práticas de RSE é evidente. Adicionalmente, há matérias de domínio comum como o voluntariado, literacia financeira, a redução dos consumos energéticos e a reflorestação.

Este estudo vem contribuir para ampliar a literatura sobre o tema, já que se apresenta escassa no domínio da comunicação de responsabilidade pelo setor bancário português. Adicionalmente, pode resultar num valioso instrumento para os gestores das instituições financeiras e outras, uma vez que apresenta várias iniciativas, o feedback de colaboradores bancários, bem como uma agenda de sugestões de iniciativas passíveis de implementação.

Aponta-se como principal limitação ao estudo a reduzida amostra, tanto ao nível das instituições bancárias alvo de análise, como dos participantes nas entrevistas realizadas. Ainda assim, este último aspeto é considerado habitual na abordagem qualitativa, uma vez que amostras volumosas geram um aglomerado de dados difíceis de analisar (Fortin, 2009).

Seria interessante que futuros estudos analisassem a informação contida nos relatórios de gestão e contas e de sustentabilidade, uma vez que assumem grande relevância como instrumento de comunicação, assim como comparar instituições bancárias portuguesas com outras europeias, no sentido de averiguar eventuais preocupações comuns ou destoantes.

\section{BIBLIOGRAFIA}

Almeida, T. A., Silva, J. D., \& Oliveira, M. C. (2015). Responsabilidade social corporativa e a influência de aspectos do ambiente institucional: uma análise no setor bancário brasileiro. Revista Universo Contábil, 11(4), 44-62.

Amorim, V. L. da C. (2010). Estudo da divulgação de informação acerca da responsabilidade social empresarial. Dissertação de mestrado.Universidade do Minho.Braga.

Andrikopoulos, A., Samitas, A., \& Bekiaris, M. (2014). Corporate social responsibility reporting in financial institutions: Evidence from Euronext. Research in International Business and Finance, 32, 27-35.

Barakat, S. R., Boaventura, J. M. G., \& Polo, E. F. (2017). Alinhamento estratégico da responsabilidade social coprorativa: um estudo de caso no setor bancário brasileiro. Revista Eletrónica de Administração, 86(1), 206-233.

Barakat, S. R., \& Polo, E. F. (2016). Implicações estratégicas da 
responsabilidade social corporativa. Revista de Gestão Social e Ambiental - RGSA, 10(2), 37-52.

BCP, M. (2017). Site Oficial do Banco Comercial Português. Acedido em dezembro de 2017 em:

https://ind.millenniumbcp.pt/pt/particulares/Pages/Welcome.aspx.

Bilhim, J. A. de F. (1996). Teoria organizacional: estrutura e pessoas $\left(1^{\mathrm{a}}\right.$ Ed). Lisboa: ACMA Artes Gráficas, Lda.

Braga, J. P., Oliveira, J. R. S., \& Salotti, B. M. (2009). Determinantes do nível de divulgação ambiental nas Demonstrações contábeis de empresas brasileiras. Revista de Contabilidade Da UFBA, 3(3), 1-21.

Brambilla, F., Candido, S., \& Gusatti, C. (2016). Desafios da comunicação institucional e do posicionamento no mercado do tabaco perante as restrições ao setor. Revista Capital Científico - Eletrônica., 14(3), 24.

Branco, M. C., \& Rodrigues, L. L. (2008). Factors influencing social responsibility disclosure by portuguese companies. Journal of Business Ethics, 83(4), 685-701.

Branco, M., \& Rodrigues, L. (2006). Communication of corporate social responsibility by Portuguese banks. Corporate Communications: An International Journal, 11(3), 232-248.

Cardoso, O. D. O. (2006). Comunicação empresarial versus comunicação organizacional: novos desafios teóricos. Revista de Administração Pública, 40(6), 1123-1144.

Cormier, D., \& Gordon, I. M. (2001). An examination of social and environmental reporting strategies. Accounting, Auditing \& Accountability Journal, 14(5), 587-617.

Decreto Lei no 89/17 de 28 de julho do Ministério das Finanças, Diário da República: I Série, $\mathrm{N}^{\circ} 145$ (2017). Disponível em: http://data.dre.pt/eli/dec-lei/89/2017/07/28/p/dre/pt/html.

Deegan, C. (2002). Introduction: The legitimising effect of social and environmental disclosures - a theoretical foundation. Accounting, Auditing \& Accountability Journal, 15(3), 282-311.

Douglas, A., Doris, J., \& Johnson, B. (2004). Corporate social reporting in Irish financial institutions. The TQM Magazine, 16(6), 387-395.

Duarte, M., Rodrigues, J., \& Sotomayor, A. (2014). Princípios de gestão das organizações $\left(2^{\mathrm{a}}\right)$. Lisboa: Rei dos livros.

Eugénio, T. P. (2010). Avanços na divulgação de informação social e ambiental pelas empresas e a teoria da legitimidade. Revista Universo Contábil, 6(1), 102-118.

Europeia, C. (2001). Livro verde - Promover uma quadro europeu para a respossabilidade social das empresas. Bruxelas. Disponível em: 
http://www.europarl.europa.eu/meetdocs/committees/empl/20020416/ doc05a_pt.pdf

Faria, M. J. da S. (2015). Determinantes da comunicação na gestão da responsabilidade social empresarial : análise do âmbito empresarial português sob a ótica da nova teoria estratégica. Tese de doutoramento. Univerdade da Coroña.

Faria, M. J. da S. (2017). Tipos de divulgação da informação financeira e não financeira de responsabilidade social empresarial. Cadernos EBAPE.BR, 15(9), 534-558.

Fortin, M.-F. (2009). O processo de investigação (5 $\left.{ }^{\mathrm{a}}\right)$. Loures: Lusociência.

Freeman, R. E. (2004). The stakeholder approach revisited. Zeitschrift Für Wirtschafts-Und Unternehmensethik, 5(3), 228-241.

Friedman, M. (1970). The social responsibility of business is to increase its profits. Corporate Ethics and Corporate Governance, 173-178.

Gil, A. C. (2008). Métodos e técnicas de pesquisa social. Journal Of The American Medical Association (6a , Vol. 264). São Paulo: Editora Atlas, SA.

Gill, D. L., Dickinson, S. J., \& Scharl, A. (2008). Communicating sustainability: A web content analysis of North American, Asian and European firms. Journal of Communication Management, 12(3), 243262.

Grace. (2014). Guia Responsabilidade Social nas Pequenas e Médias Empresas. Disponível em: http://www.grace.pt/conteudos/00/04/00/00/GUIA-RS-NASPME_SITE_9985.pdf.

Greenwood, M., \& De Cieri, H. (2005). Stakeholder theory and the ethics of human resource management. Human resource management ethics and employment, 1-17.

Kunsch, M. M. K. (2011). Comunicação organizacional e relações públicas: Perspetivas dos estudos latino - americanos. Revista Internacional de Relaciones Públicas, I(1), 69-96.

Lungu, C. I., Caraiani, C., Dascalu, C., \& Guse, R. G. (2011). Exploratory study on social and environmental reporting of european companies in crises period. Accounting and Management Information Systems, 10(4), 459-478.

Magalhães, R. S. (2010). Lucro e reputação: interações entre bancos e organizações sociais na construção das políticas socioambientais. Tese de doutoramento. Universidade de São Paulo.

Marco, D. A. R. do. (2012). As funções da responsabilidade social no 
marteking social de hoje. O caso de estudo McDonald's Portugal. Dissertação de mestrado. Universidade Católica Portuguesa. Lisboa.

Matei, M., \& Voica, M. C. (2013). Social responsibility in the financial and banking sector. Economic Insights - Trends \& Challenges, 65(1), 115123.

McWilliams, A., \& Siegel, D. S. (2011). Creating and capturing value: strategic corporate social responsibility, resource-based theory, and sustainable competitive advantage. Journal of Management, 37(5), 1480-1495.

McWilliams, A., Siegel, D. S., \& Wright, P. M. (2006). Corporate social responsibility: strategic implications. Journal of Management Studies, 43(1), 1-18.

Monteiro, S. (2012). A comunicação como fator homeostático na exploração de TI em contexto empresarial. Dissertação de mestrado. Universidade Católica Portuguesa. Porto.

Neves, J. C. das. (2008). Introdução à ética empresarial. Lisboa: Princípia. O'Donovan, G. (2002). Environmental disclosures in the annual report: Extending the applicability and predictive power of legitimacy theory. Accounting, Auditing \& Accountability Journal, 15(3), 344-371.

Parisotto, I. R. dos S., \& Souza, M. T. S. (2012). Investimento sócioambiental de bancos brasileiros. Revista Eletrónica de Gestão Organizacional, 10(1), 53-83.

Patten, D. M. (2002). Give or take on the Internet: na examination of the disclosure practices of insurance web innovators. Journal of Business Ethics (Vol. 36).

Penha, E. D. dos S., Andrade, A. G., Cabral, A. C. de A., \& Parente, T. C. (2013). O processo de institucionalização da responsabilidade social: um estudo no setor bancário. Revista Pensamento \& Realidade, 28(1), $45-65$.

Rego, A. (1999). Comunicação nas organizações (1ª). Lisboa: Edições Sílabo, Lda.

Rodrigues, I. M. D. (2013). A crise e o relato de sustentabilidade no setor bancário : o caso português. Dissertação de mestrado. Universidade do Porto. Porto.

Ruão, T. (1999). A comunicação organizacional e a gestão de recursos humanos. Evolução e actualidade. Cadernos Do Noroeste, 12(1-2), 179-194.

Rumo, B. (2006). Responsabilidade Empresarial: da teoria à prática. Porto: Artes gráficas. Disponível em: http://www.bcsdportugal.org/wp-content/uploads/2013/10/Anuarios- 
BCSD-2006.pdf.

Silva, A. R. M. (2014). A divulgação da responsabilidade social empresarial nas empresas do PSI geral da Euronext Lisboa (20122013). Relatórios de sustentabilidade vs Divulgação online. Dissertação de mestrado. Instituto Politécnico de Lisboa. Lisboa.

Surroca, J., Tribó, J. A., \& Waddock, S. (2010). Corporate responsability and financial performe: the role of intangible resources. Strategic Management Journal, 31(5), 463-490.

Teixeira, S. (2005). Gestão das organizações ( $2^{\mathrm{a}}$ ). Lisboa: McGraw-Hill. Thompson, P., \& Cowton, C. J. (2004). Bringing the environment into bank lending: Implication for environmental reporting. British Accounting Review, 36(2), 197-218.

Wilmshurst, T. D., \& Frost, G. R. (2000). Corporate environmental reporting: A test of legitimacy theory. Accounting, Auditing \& Accountability Journal, 13(1), 10-26.

Zientara, P. (2017). Socioemotional Wealth and Corporate Social Responsibility: A Critical Analysis. Journal of Business Ethics, 144(1), 185-199. 